УДК 019.941: 598.4

\title{
СЛУЧАЙ МАССОВОЙ ГИБЕЛИ ТОНКОКЛЮВОГО БУРЕВЕСТНИКА PUFFINUS TENUIROSTRIS (TEMMINCK, 1835) НА ЗАПАДНОЙ ЧУКОТКЕ
}

\author{
Соловьева Д. В. ${ }^{1}$ Регель К. В. ${ }^{1}$, Павлюков К. $\Gamma_{.}^{1}$, Павлюков Г. К. ${ }^{2}$ \\ ${ }^{I}$ ФБУН Институт биологических проблем Севера ДВО РАН, г. Магадан \\ ${ }^{2}$ ФГБОУ ВО «Санкт-Петербургский государственный университет гражданской авиации», \\ г. Санкт-Петербург \\ E-mail: diana_solovyova@mail.ru
}

\begin{abstract}
Массовая гибель тонкоклювых буревестников отмечена в период с 27 октября по 7 ноября 2018 г. на восточном берегу Чаунской губы, на о. Айон и на оз. Тытыль, Западная Чукотка. По нашим оценкам, здесь погибло около полумиллиона птиц. Причиной массового залета в нехарактерные области Северного Ледовитого океана (более 500 км на запад от известных областей зимовок) явилась аномально высокая температура поверхностных вод этой части океана в сентябре 2018 г. Буревестники задержались с отлетом из области аномальной зимовки почти на 1.5 мес дольше по сравнению со средней датой отлета в 2008 г. У двух погибших птиц выявлена слабая зараженность гельминтами: обнаружены 2 вида цестод и 3 вида нематод.
\end{abstract}

Ключевые слова: тонкоклювый буревестник, Puffinus tenuirostris, массовая гибель, гельминты, Западная Чукотка.

DOI: $10.34078 / 1814-0998-2020-2-93-97$

\section{ВВЕДЕНИЕ}

Тонкоклювый буревестник Puffinus tenuirostris (Temminck, 1835) - один из самых массовых видов птиц в мире, численность мировой популяции оценивается в 23 млн гнездящихся птиц (Scira, 1991). Это небольшая морская птица (массой до 500 г) отряда Трубконосые (Procellariiformes) семейства Буревестниковые (Procellariidae). Гнездится на океанических островах вдоль юго-восточного побережья Австралии и на о. Тасмания (BirdLife International, 2018). Во внегнездовое время тонкококлювые буревестники совершают кольцеобразную миграцию из района размножения через весь Тихий океан до Берингова и Чукотского морей. Негнездовые птицы покидают колонии в марте, за ними следуют взрослые размножавшиеся птицы (отлет в апреле-мае), затем отлетает молодняк первого года (Marchant, Higgins, 1990). Обратная миграция из мест зимовки (Чукотское и Берингово моря) на юг начинается в начале сентября и заканчивается в местах размножения в конце сентября - начале октября (Serventy, 1967). В последние десятилетия вследствие климатических изменений наблюдается прогрессирующее расширение области

(С Соловьева Д. В., Регель К. В., Павлюков К. Г., Павлюков Г. К., 2020 кочевок и увеличение численности данного вида в Чукотском море (Gall et al., 2013). В Беринговом море крупные концентрации тонкоклювого буревестника наблюдаются до конца октября и даже в ноябре (Шунтов, 1998; Gibson, Byrd, 2007). Для вида характерна массовая гибель в отдельные годы: около 400 тыс. тонкоклювых буревестников погибло в Беринговом море в августе-сентябре 1997 г., при последующих учетах на тех же линейных трансектах в этом море в 1998 и 1999 г. гибели не выявлено (Hyrenbach et al., 2001). Специальных исследований гельминтов тонкоклювого буревестника в Северной Пацифике и прилегающих акваториях арктического бассейна не проводили. Лишь один вид нематод (Seuratia puffini Yamaguti, 1961) обнаружен у тонкоклювого буревестника из Берингова моря (Леонов и др., 1964).

\section{МЕТОДЫ}

Наблюдения за массовой гибелью тонкоклювых буревестников были инспирированы собственно фактом массового появления и гибели птиц. Наблюдения на Чаунском биологическом стационаре проводили ежедневно в период с 20 октября по 15 ноября. Скопление трупов и умирающих птиц фотографировали при помощи мобильного телефона (К. Г. Павлюков). Расчеты, сделанные по фотографии, позволяют оценить плотность трупов в местах массовой гибели. Эти 
расчеты основаны на среднем расстоянии между трупами в корпусах птицы (корпус птицы 30 см). Учет трупов птиц со снегохода «Буран» был проведен 2 ноября на маршруте между с. Рыткучи и Чаунским стационаром, протяженностью 17 км, дистанция обнаружения трупов была принята за 50 м. Были использованы также данные наблюдений жителей с. Рыткучи, совершавших регулярные поездки в г. Певек на снегоходах по маршруту, соответствующему серой линии на рис. 1.

Снегоходные поездки по р. Пучьэвеем и по предгорьям г. Нейтлин не выявили массовой гибели тонкоклювых буревестников в этом районе. Для оценки количества погибших птиц мы приняли минимальную ширину полосы распространения трупов вдоль восточного берега Чаунской губы за 13 км (расстояние от берега до южного конца о. Айопечан, где мертвые буревестники были отмечены) и длину этой полосы за 146 км. Сообщения местных оленеводов из с. Айон и золотодобытчиков рудника «Купол» были использованы для экстраполяции площади, покрытой трупами птиц, все сообщения сопровождались фотографиями. В июле 2019 г. на Чаунском стационаре вскрыты (К. В. Регель) две замороженные птицы (обе сам-

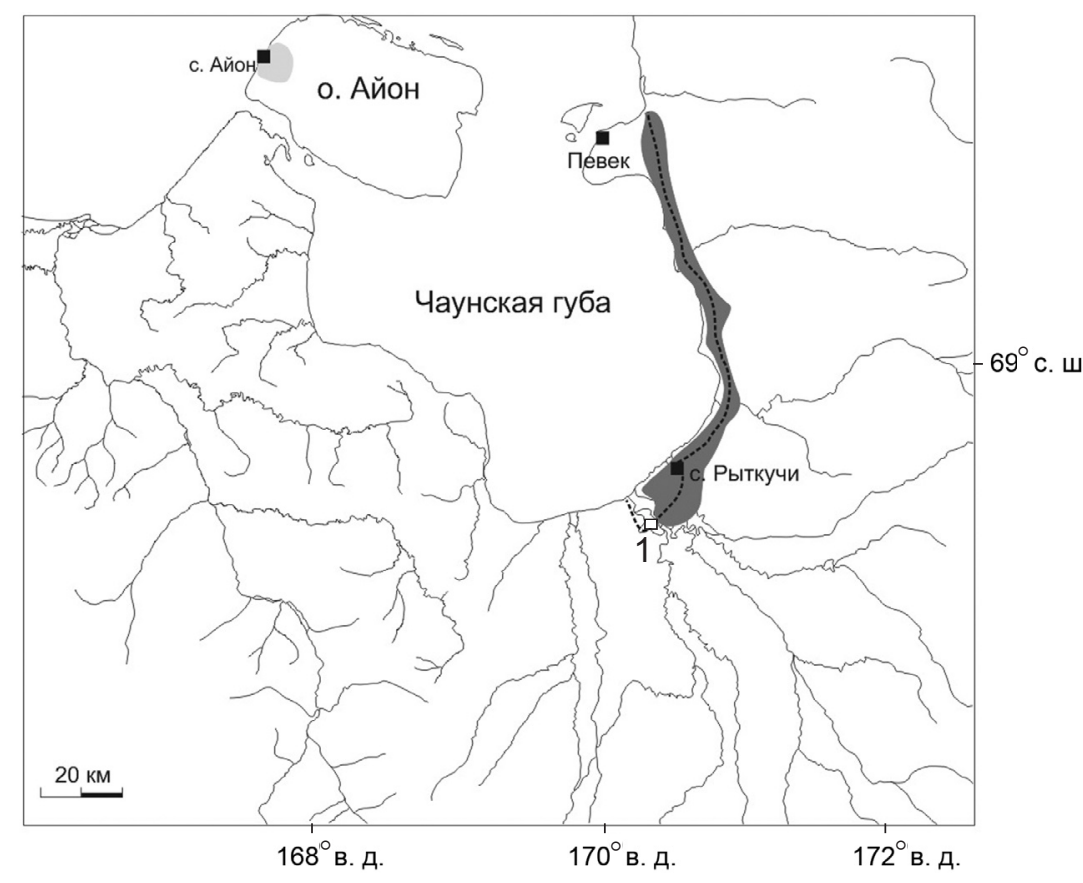

Puc. 1. Карта района исследований на Западной Чукотке. Снегоходные маршруты наблюдений за гибелью птиц обозначены черной пунктирной линией; район массовой гибели птиц - темно-серое закрашивание; район единичной гибели птицы - светло-серое закрашивание. Чаунский стационар обозначен цифрой 1

Fig. 1. Map of the study area in the Western Chukotka. Snowmobile survey routes are marked by the black dashed line; the mass mortality area is dark grey; lesser mortality, light grey. 1 marks the Chaun biostation ки, одна молодая, вторая явно гнездившаяся с развитым яйцеводом) и собраны гельминты желудочно-кишечного тракта. Фотографии цестод (окрашенных кармином по Блажину) и нематод (просветленных глицерином или смесью глицерина с молочной кислотой) сделаны с использованием микроскопов Axiolab c фотонасадкой AxioCam MR3.

\section{РЕЗУЛЬТАТЫ И ОБСУЖДЕНИЕ}

Стаи тонкоклювых буревестников появились на Чаунском биологическом стационаре, Чаунский район Чукотского АО (68ㄷ' с. ш., 170³' в. д.) 27 октября 2018 г., с 28 октября птицы начали массово умирать в тундре. В одном поле фотографии мобильным телефоном визуально определено 98 трупов и умирающих птиц. На маршруте между с. Рыткучи и Чаунским стационаром 2 ноября было учтено более 150 трупов. Концентрация трупов буревестников отмечена по всему маршруту вдоль восточного побережья Чаунской губы (см. рис. 1) от с. Рыткучи до пос. Апапельгино к северу от г. Певек. Еще летевших и умирающих буревестников наблюдали в окрестностях с. Айон на о. Айон 4 ноября, хотя большая часть птиц здесь летала, трупов было немного (М. В. Эттувги, личное сообщение и фото). 7 ноября умирающего буревестника подобрали глубоко в материковой части Западной Чукотки на оз. Тытыль с координатами 674' с. ш., 1694' в. д. (А. Апока, личное сообщение и фото).

Плотность погибших птиц на маршруте длиной 17 км при учете дистанции обнаружения трупа на снегу в 50 м составила 188 трупов/км². На восточном побережье Чаунской губы в полосе шириной 13 км погибло не менее 350 тыс. тонкоклювых буревестников. Расчеты, сделанные по фотографии с о. Айопечан, позволяют оценить плотность трупов в 0.4

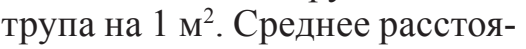
ние между трупами в корпусах птицы составило 4.23 корпуса, или 126 см. Таким образом, в местах концентрации мертвых птиц могло быть до нескольких тысяч. Учитывая географический размах гибели, мы предполагаем, что в конце октября - начале ноября 2018 г. на Западной Чукотке погибло не менее полумиллиона тонкоклювых буревестников. 
Зимовочный ареал тонкоклювого буревестника охватывает все моря Северной Пацифики, концентрированные зимовки отмечены по обеим сторонам от Алеутской гряды и вокруг Японских островов (Carey et al., 2014). Согласно исследованию с использованием геолокаторов в 2008 г., взрослые птицы покидали пределы зимовочного ареала в Чукотском и Беринговом морях в среднем $26 \pm 7$ сентября (среднее из 20 птиц), и птицы, помеченные геолокаторами, не отмечались западнее о. Врангеля (Carey et al., 2014). Случай гибели тонкоклювых буревестников отмечен на о. Врангеля 12 сентября 2017 г., птицы достоверно погибли до 12 сентября, и трупы были принесены на остров штормом (Бабий, 2018). В случае наших наблюдений тонкоклювые буревестники оказались на 450 км западнее о. Врангеля (в Чаунской губе) и задержались здесь до начала ноября, т. е. на 40 дней дольше, чем дата среднего отлета в 2008 г. Исторически тонкоклювые буревестники не были отмечены в Чаунской губе (Кречмар и др., 1991). Мы нашли два трупа птиц этого вида на северном побережье о. Айопечан в июле 2012 г. (птицы погибли годом ранее), что свидетельствует о том, что эти птицы гибнут на берегах губы не в первый раз. Мы предполагаем, что причиной проникновения тонкоклювого буревестника далеко на запад является потепление климата, особенно заметное в осенние сезоны. Осень 2018 г. на Чаунском стационаре была длинной и теплой, в глобальном масштабе отмечена небывало высокая температура поверхностных вод Берингова (на $3^{\circ} \mathrm{C}$ выше средней за $1981-$ 2010 гг.) и особенно Чукотского моря (на $4^{\circ} \mathrm{C}$ выше) в сентябре 2018 г. (Weather Nation, 2018). В Северном Ледовитом океане минимальные площади морского льда в последнюю декаду октября наблюдались в 2012, 2016 и 2018 г. (National..., 2018). Однако массовая гибель тонкоклювых буревестников отмечена толь- ко в 2018 г., что, вероятно, обусловлено проникновением птиц далеко на запад, что стало возможным при аномально высоких температурах поверхностных вод океана.

Поскольку птицы были отмечены летящими с запада на о. Айон, можно предположить, что они проникли в глубь Северного Ледовитого океана слишком далеко на запад и не успели покинуть район до сильных заморозков, что и вызвало их массовую гибель от холода. Согласно данным архива погоды на метеостанции Рыткучи, резкое похолодание с переходом средних (за 3 дня)

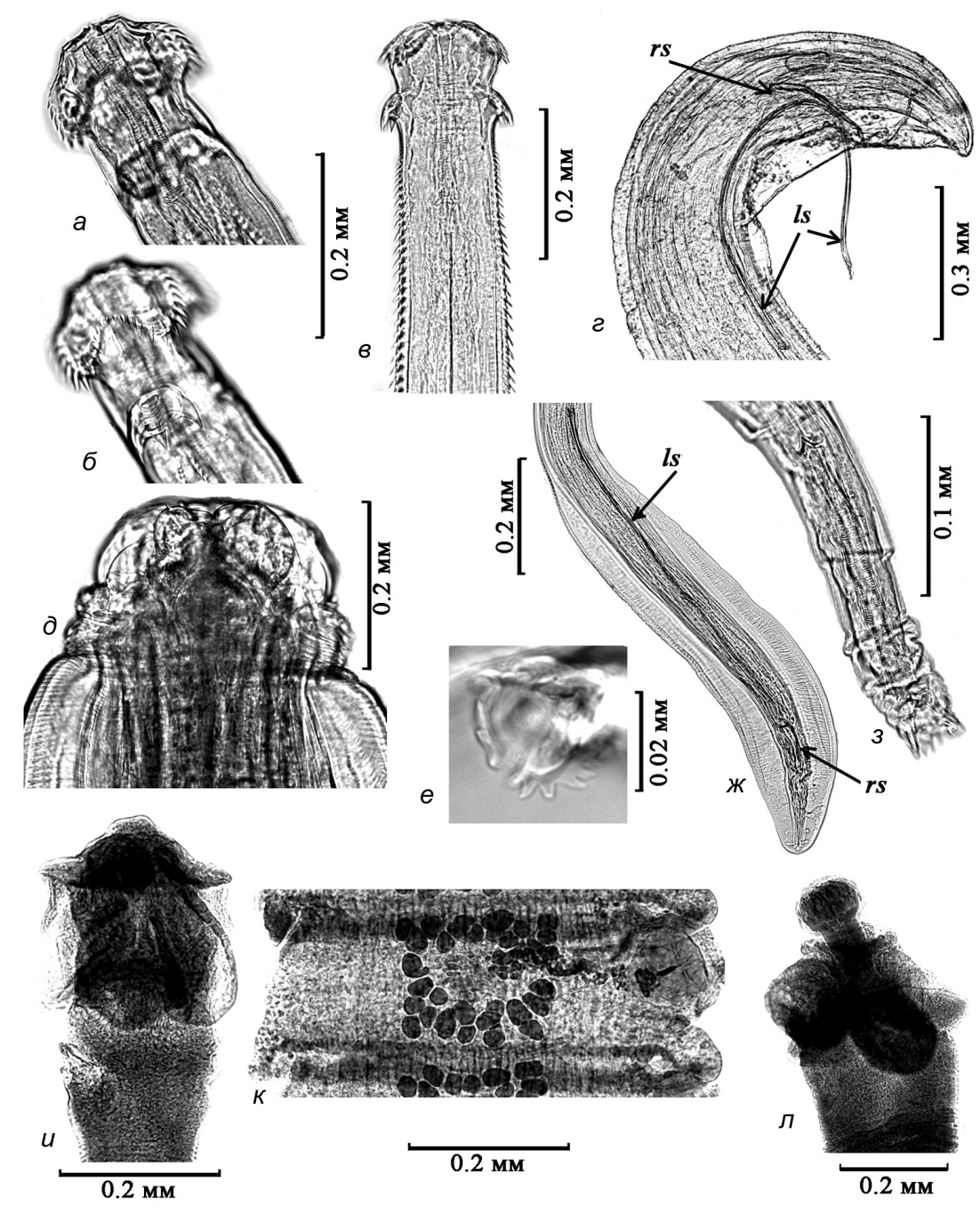

Puc. 2. Гельминты двух погибших буревестников: Seuratia puffini, передний отдел тела самки $(a, \sigma)$ и самца $(8)$, задний конец тела самца (2); Contracaecum sp., головной конец (d); Stegophorus sp., «голова» и задний отдел тела самца (e, ж), передний отдел тела самки (з); Tetrabothrius cylindraceus, сколекс $(u)$, гермафродитный членик $(\kappa)$; Dilepididae gen. sp. сколекс (л). Обозначения: $l s$ - левая спикула; $r s$ - правая спикула

Fig. 2. Helminthes of the two dead short-tailed shearwaters: Seuratia puffini, anterior regions of the female $(a, \sigma)$ and the mail $(b)$, posterior region of mail (2); Contracaecum sp., anterior end (d); Stegophorus sp., "head" and posterior region of mail $(e, \%)$, anterior region of female (3); Tetrabothrius cylindraceus, scolex $(u)$, hermaphroditic proglottide $(\kappa)$; Dilepididae gen. sp. scolex $(\pi) . l s$ - left (larger) spicule; $r s$ - right (smaller) spicule 
температур от $-8.6^{\circ} \mathrm{C}$ (минимальная температуpa $-12^{\circ} \mathrm{C}$ ) до $-18.5^{\circ} \mathrm{C}$ (минимальная температуpa $-26^{\circ} \mathrm{C}$ ) произошло 26 октября 2018 г., т. е. за 1 день до первой регистрации гибнущих буревестников (Weather..., 2019). Поскольку буревестники не могут взлетать с земли, причиной их гибели на Чукотке было «вынужденное приземление», по-английски grounding, являющееся обычной причиной гибели птиц этот вида (Rodriguez et al., 2014).

В 1980-е гг. ежегодный прирост популяции тонкоклювого буревестника за счет молодняка составлял около 28 млн птиц (11.5 млн пар, при 19\% неразмножающихся птиц и успехе размножения в 3.1 слетка на успешную пару; Skira, 1991). Смертность молодняка в первый год жизни составляла $52 \%$, т. е. за первый год могло гибнуть до 14 млн особей. Если принять, что на Западной Чукотке погибли преимущественно молодые птицы, то даже оцененная нами гибель в 0.5 млн особей является естественной для этого вида и не скажется на потенциале популяции.

Две вскрытые нами птицы имели высокую жирность, т. е. не были истощены, что может указывать на гибель от переохлаждения, a не от голода. В желудках птиц отсутствовали свежие остатки пищи, обнаружены лишь (возможно, выполнявшие роль гастролитов) одиночные кусочки гравия, гидрофобные частицы растительного происхождения (семена чины Lathyrus japonicas, остатки древесины и др.), а также угольный шлак и фрагменты пластика, вероятно собранные птицами на поверхности воды. При вскрытии пищеварительного тракта у обеих птиц найдены нематоды и цестоды.

В пищеводе молодого буревестника собраны нематоды: 3 самки и 2 самца $S$. puffini (Acuariidae), а у взрослой птицы - 1 самец $S$. puffini (рис. 2, a-г) и 3 зрелые самки Contracaecum sp. (Anisakidae) (рис. 2, d). Под кутикулой желудков обеих птиц обнаружены зрелые нематоды Stegophorus sp. (Acuariidae) (суммарно 14 самок и 9 самцов) (рис. $2, e, ж)$. В кишечнике молодой самки собран десяток цестод Tetrabothrius cylindraceus (Rud., 1819) (Tetrabothriidae) (рис. 2, 3, $u$ ) и сколекс Dilepididae gen. sp. с утерянными крючьями хоботка (рис. 2, к). У взрослой птицы, пищеварительный тракт которой был зафиксирован формалином и вскрыт через 3 мес, в кишечнике обнаружены деформированные неидентифицируемые фрагменты единичных цестод. Интенсивность инвазии гельминтами столь низка, что не могла служить причиной гибели птиц.

\section{БЛАГОДАРНОСТИ}

Авторы благодарят Чукотскую горно-геологическую компанию за полную транспортную и логистическую поддержку орнитологических исследований на Чукотке.

\section{ЛИТЕРАТУРА}

Бабий У. В. О падеже морских птиц в акватории острова Врангеля в сентябре 2017 года // Рус. Орнитол. Журн. 2018. № 27 (1605). С. 2136-2137.

Кречмар А. В., Андреев А. В., Кондратьев А. Я. Птицы северных равнин. Л. : Наука, 1991. 288 с.

Леонов В. А., Белогуров О. И., Цимбалюк А. К. Seuratia puffini Yamaguti, 1941 - новый для фауны СССР род и вид нематод // Зоол. журн. 1964. № 43 (6). C. $930-932$.

Шунтов В. П. Птицы дальневосточных морей России. Владивосток : ТИНРО, 1998. Т. 1. 423 с.

BirdLife International, 2018. Ardenna tenuirostris. The IUCN Red List of Threatened Species 2018: e.T22698216A132635686. http://dx.doi.org/10.2305/ IUCN.UK.2018-2.RLTS.T22698216A132635686.en. Downloaded on 22 January 2019.

Carey M. J., Phillips R. A., Silk J. R. D., Shaffer S. A. Trans-equatorial migration of short-tailed shearwaters revealed by geolocators // Emu. 2014. Vol. 114, No. 4. 352359. http://dx.doi.org/10.1071/MU13115

Gall A. E., Day R. H., Weingartner T. J. Structure and variability of the marine-bird community in the northeastern Chukchi Sea // Continental Shelf Resources. 2013. 67. P. 96-115.

Gibson D. D., Byrd G. V. Birds of the Aleutian Islands, Alaska. Series in ornithology (Vol. 1) AK: Nuttall Ornithological Club, 2007. $351 \mathrm{p}$.

Hyrenbach K. D., Baduini C. L., Hunt Jr. G. L. Line transect estimates of short-tailed shearwater Puffinus tenuirostris mortality in the south-eastern Bering Sea, 19971999 // Marine Ornithology. 2001. No. 29 (1). P. 11-18.

Marchant S., Higgins P. J. (eds.). Handbook of Australian, New Zealand and Antarctic Birds. Vol. 1: Ratites to Ducks. Part A: Ratites to Petrels. Melbourne : Oxford University Press, 1990.

National Snow and Ice Data Center. https://nsidc. org/arcticseaicenews/charctic-interactive-sea-ice-graph Downloaded on 22 January 2019. 2018

Rodríguez A., Burgan G., Dann P., Jessop R., Negro J. J., Chiaradia A. Fatal attraction of short-tailed shearwaters to artificial lights. PLoS One. 2014.9 (10): e110114.

Serventy D. L. Aspects of the population ecology of the shorttailed shearwater Puffinus tenuirostris // Proceedings of the $14^{\text {th }}$ International Ornithological Congress, 24 30 July 1966, Oxford, UK, 1967. P. 185-190.

Skira I. The short-tailed shearwater: a review of its biology // Corella. 1991. No. 15 (2). P. 45-52.

Weather archive in Chaun. https://rp5.ru/Weather_archive in Chaun. Downloaded on 15 September 2019.

Weather Nation. http://www.weathernationtv.com/ news/alaskas-2018-early-fall-extremes/ Downloaded on 22 January 2019. 2018. 


\title{
CASE OF MASS MORTALITY OF THE SHORT-TAILED SHEARWATER PUFFINUS TENUIROSTRIS (TEMMINCK, 1835) IN WESTERN CHUKOTKA
}

\author{
D. V. Solovyeva', K. V. Regel ${ }^{1}$ K. G. Pavluykov', G. K. Pavluykov' \\ ${ }^{1}$ Institute of Biological Problems of the North, FEB RAS, Magadan \\ ${ }^{2}$ Saint-Petersburg State University of Civil Aviation, St. Petersburg
}

\begin{abstract}
Mass mortality of short-tailed shearwaters was recorded along the east coast of the Chaun Bay, on the Ayon Island and on the Tytyl Lake, all in Western Chukotka, between October 27 and November 7, 2018. We estimated half a million dead birds there. Ocean surface temperature anomaly in September 2018 was a key reason for the birds mass intrusion to the Arctic Ocean, over $500 \mathrm{~km}$ further west of the known wintering waters. Shearwaters delayed to depart the abnormal wintering area for almost 1.5 months, compared to the mean 2008 departure date. Two dead birds exposed slight helminth infection: 2 species of cestodes and 3 species of nematodes were found.
\end{abstract}

Keywords: short-tailed shearwaters, Puffinus tenuirostris, mass mortality, helminths, Western Chukotka.

\section{REFERENCES}

Babiy, U. V., 2018, On Mortality of Seabirds in the Waters Adjusted to the Wrangel Island in September 2017, Russian Ornithological Journal, 27 (1605), 21362137 [In Russian].

BirdLife International, 2018, Ardenna tenuirostris, The IUCN Red List of Threatened Species 2018: e.T22698216A132635686, http://dx.doi.org/10.2305/ IUCN.UK.2018-2.RLTS.T22698216A132635686.en.

Carey, M. J.; Phillips, R. A.; Silk, J. R. D.; Shaffer, S. A., 2014, Trans-Equatorial Migration of Short-Tailed Shearwaters Revealed by Geolocators, Emu, 114, 4, 352359, http://dx.doi.org/10.1071/MU13115

Hyrenbach, K. D.; Baduini, C. L.; Hunt Jr. G. L., 2001, Line Transect Estimates of Short-Tailed Shearwater Puffinus tenuirostris Mortality in the South-Eastern Bering Sea, 1997-1999, Marine Ornithology, 29 (1), $11-18$

Gall, A. E.; Day, R. H.; Weingartner, T. J., 2013, Structure and Variability of the Marine-Bird Community in the Northeastern Chukchi Sea, Continental Shelf Resources, 67, 96-115.

Gibson, D. D.; Byrd, G. V., 2007, Birds of the Aleutian Islands, Alaska, Series in Ornithology, Vol. 1, AK : Nuttall Ornithological Club.

Krechmar, A. V.; Andreev, A. V.; Kondratiev, A. Ya., 1991, Birds of Northern Plains, Leningrad, Nauka [In Russian].
Leonov, V. A.; Belogurov, O. I.; Tsymbaluyk, A. K., 1964, Seuratia puffini Yamaguti, 1941 - New Genus and Species for the Fauna of USSR, Zoologicheskii Zhurnal, 43 (6), 930-932 [In Russian].

Marchant, S.; Higgins, P. J., 1990, (Eds.), Handbook of Australian, New Zealand and Antarctic Birds, Vol. 1, Ratites to Ducks, Part A, Ratites to Petrels, Melbourne, Oxford University Press.

National Snow and Ice Data Center, 2018, https:// nsidc.org/arcticseaicenews/charctic-interactive-sea-icegraph/

Rodríguez, A.; Burgan, G.; Dann, P.; Jessop, R.; Negro, J. J.; Chiaradia, A., 2014, Fatal Attraction of Short-Tailed Shearwaters to Artificial Lights, PLoS One, 9 (10): e110114.

Serventy, D. L., 1967, Aspects of the Population Ecology of the Shorttailed Shearwater Puffinus tenuirostris, Proceedings of the $14^{\text {th }}$ International Ornithological Congress, 24-30 July 1966, Oxford, UK, 185-190.

Shuntov, V. P., 1998, Birds of Far-Eastern Seas of Russia,Vladivostok, TINRO, 1 [In Russian].

Skira, I., 1991, The Short-Tailed Shearwater: a Review of Its Biology, Corella, 15, 45-52.

Weather Archive in Chaun. https://rp5.ru/Weather archive in_Chaun, downloaded on September 15, 2019.

Weather Nation, 2018, http://www.weathernationtv. com/news/alaskas-2018-early-fall-extremes/ 